\title{
Improved Analytic Hierarchy Process Based on Triangular Fuzzy Number
}

\author{
Manhong Lu \\ Department of Mathematics \\ East China University of Science and Technology \\ Shanghai, China \\ E-mail: lumanhong11@163.com
}

\author{
Kunping Zhu* \\ Department of Mathematics \\ East China University of Science and Technology \\ Shanghai, China \\ E-mail: kpzhu@ecust.edu.cn
}

\begin{abstract}
The main purpose of this paper was to improve the analytic hierarchy process and increase its credibility. We combine the Fuzzy Comprehensive Evaluation (FCE) with the Analytic Hierarchy Process (AHP) and use delphi method and triangular fuzzy numbers to establish the final fuzzy judgment matrix. Finally, we apply examples to illus trate that the improved fuzzy analytic hierarchy process can not only accurately solve the required problems, but also greatly reduce the errors caused by subjective judgments of experts, and effectively improve the accuracy of solution. However, the improved fuzzy analytic hierarchy process of this paper is a bit cumbersome, and the simpler and more efficient method is worth our searching.
\end{abstract} method

Keywords-AHP; FAHP; triangular fuzzy number; Delphi

\section{StATEMENT OF PRoBlem}

Analytic Hierarchy Process (AHP) is a hierarchical weight decision analysis method developed by Thomas L. Saaty in the early 1970s. It decomposes the elements that are always related to the decision-making into objectives, criteria, programs, etc., and makes qualitative and quantitative analysis based on it. The main steps of the AHP can be summarized as the following five steps [1]:

- Establish a hierarchy model: The decision objectives, decision criteria, and decision objects should be divided into the highest, middle, and lowest levels according to their relationships, and a hierarchy diagram should be drawn.

- Constructing a judgment matrix: Analyze the relationships among various factors in the system, compare the importance of each element at the same level with a criterion in the previous level, and obtain a judgment matrix;

- Determine the weights: Calculate the relative weights of the compared elements for the criterion from the judgment matrix

\section{- Consistency test:}

- Hierarchical total ranking: The process of determining the weighting of all factors of a certain level for the relative importance of the total goal is called the total ranking of levels. This process is carried out in order from the highest level to the lowest level. For the highest level, the result of the hierarchical sorting is the result of the total sorting.
AHP is a classical multi-attribute decision-making method and has been applied in many fields [2-3]. However, AHP still has some shortcomings:

First, it is easy to be influenced by subjective factors of experts when establishing the judgment matrix, especially when there are many factors, the workload of the scale is too large, which easily leads to the chaos of expert judgment.

Second, it is hard to calculate when the order of judgment matrix is large.

Third, there are many qualitative indicators, while the quantitative data is relatively small, which is unconvincing.

\section{Fuzzy Analytic Hierarchy Process}

\section{A. Introduction of Fuzzy Analytic Hierarchy Process}

Fuzzy Analytic Hierarchy Process (FAHP) method is an evaluation method that combines Fuzzy Comprehensive Evaluation (FCE) with Analytic Hierarchy Process (AHP). It is a combination of qualitative and quantitative analysis. The evaluation model is generally first to determine the set of factors using AHP, and then use the FCE to determine the effect of the judgment.

\section{B. Establish a fuzzyjudgment matrix}

\section{1) The introduction of triangular fuzzy number [4-5]}

If the fuzzy number a can be determined by $(\mathrm{l}, \mathrm{m}, \mathrm{u}), 0 \leqslant \mathrm{l}$ $\leqslant \mathrm{m} \leqslant \mathrm{u} \leqslant 1$, and the membership function is:

$$
\mu_{\mathrm{a}}(\mathrm{x})=\left\{\begin{array}{rc}
0 & x<l \\
\frac{x-l}{m-l} & l \leq x<m \\
\frac{u-x}{u-m} & m \leq x<u \\
0 & x \geq u
\end{array}\right.
$$

then a is called a standard triangular fuzzy number, and marked by $\mathrm{a}=(\mathrm{l}, \mathrm{m}, \mathrm{u})$. when $\mathrm{l}=\mathrm{m}=\mathrm{u}$, a is an exact number. $\mathrm{l}$ is the most conservative estimate, the lower bound of the triangular fuzzy number, $\mathrm{m}$ is the most probable estimate, and $\mathrm{u}$ is the most optimistic estimate, the upper bound of the triangular fuzzy number. We define the following operation rules:

$$
a_{1} \oplus a_{2}=\left(l_{1}+l_{2}, m_{1}+m_{2}, u_{1}+u_{2}\right)
$$




$$
a_{1} \otimes a_{2}=\left(l_{1} I_{2}, m_{1} m_{2}, u_{1} u_{2}\right)
$$

Because the triangular fuzzy number includes not only the concept of the interval, but also the median value that shows the most likely relationship between the indicators. Its characteristics can better reflect the subjective evaluators' understanding of the important relationships among the indicators. Therefore, this paper chooses FAHP based on triangular fuzzy numbers [6].

\section{2) Establish the judgment matrix}

Using the Delphi method [7], several experts are invited to make comparisons of the importance of the same level with each other, and the triangular fuzzy numbers were used to construct triangular fuzzy number complementary judgment matrix. There are $\mathrm{N}$ evaluation indicators, the judgment matrix is $\mathrm{B}=\left(b_{i j}\right)_{n \times n}$, where

$$
\begin{aligned}
& b_{i j}=\left[l_{i j}, m_{i j}, u_{i j}\right], \quad l_{i i}=0.5, \quad m_{i i}=0.5, \\
& u_{i i}=0.5, \quad m_{i j}+m_{j i}=1, \quad l_{i j}+u_{i j}=1 .
\end{aligned}
$$

What's more, the elements of the judgment matrix are given a specific value from 0 to 1 scale, and the average value of the judgment matrix of multiple experts is averaged to obtain the final fuzzy judgment matrix B as follows:

$\mathbf{B}=\left[\begin{array}{ccc}{\left[l_{11}, m_{11}, u_{11}\right]} & \cdots & {\left[1_{1 n}, m_{1 n}, u_{1 n}\right]} \\ \vdots & \ddots & \vdots \\ {\left[1_{n 1}, m_{n 1}, u_{n 1}\right]} & \ldots & {\left[1_{n n}, m_{n n}, u_{n n}\right]}\end{array}\right]$

TABLE I. THE 0 1 SCALE METHOD

\begin{tabular}{|c|c|}
\hline Scaling & Description \\
\hline 0.9 & The former is extremely more important than the latter \\
\hline 0.8 & The former is strongly more important than the latter \\
\hline 0.7 & The former is obviously more important than the latter \\
\hline 0.6 & The former is slightly more important than the latter \\
\hline 0.5 & The former is as important as the latter \\
\hline 0.4 & The latter is slightly more important than the former \\
\hline 0.3 & The latter is obviously more important than the former \\
\hline 0.2 & The latter is strongly more important than the former \\
\hline 0.1 & The latter is extremely more important than the former \\
\hline
\end{tabular}

\section{Determine the weight}

Calculate the sum of the rows of the triangular fuzzy complementary judgment matrix $\mathrm{B}$ and normalize it to get the weights [8].

$$
\mathrm{W}_{\mathrm{i}}=\left(\frac{\sum_{j=1}^{n} l_{\mathrm{ij}}}{\sum_{i=1}^{n} \sum_{j=1}^{n} l_{\mathrm{ij}}}, \frac{\sum_{j=1}^{n} m_{\mathrm{ij}}}{\sum_{i=1}^{n} \sum_{j=1}^{n} m_{\mathrm{ij}}}, \frac{\sum_{i=1}^{n} u_{\mathrm{ij}}}{\sum_{i=1}^{n} \sum_{j=1}^{n} u_{\mathrm{ij}}}\right)
$$

And then feedback the results to experts, the experts give the weight of each index independently, and collect the result and calculate the mean $w_{i}=\frac{1}{n} \sum_{k=1}^{n} w_{i}^{(k)}$ and standard deviation of the weight of each index $\sigma_{i}=\sqrt{\frac{1}{n-1} \sum_{k=1}^{n}\left(w_{i}^{(k)}-w_{i}\right)^{2}}$. And then the average and standard deviation of the results returned to the experts, requiring experts to redefine the weight on the new basis. Repeat the above steps until the deviation of each index weight and its average value does not exceed the predetermined range, that is, the opinions of all experts basically converge. At this time, the average weight of each index is the final weight.

\section{APPLICATION EXAMPLE}

In the case of selecting materials for industrial design as an example, what kind of materials should be used to manufacture a cheap, sturdy chair? Then use the above method to select the best material.

\section{A. Establish a hierarchy structure model}

Now only consider three materials: plastic, wood and steel. Manufacturing a chair must take into account many aspects such as manufacturing costs, material properties, modeling and environmental costs. Therefore, the following hierarchical model can be established:

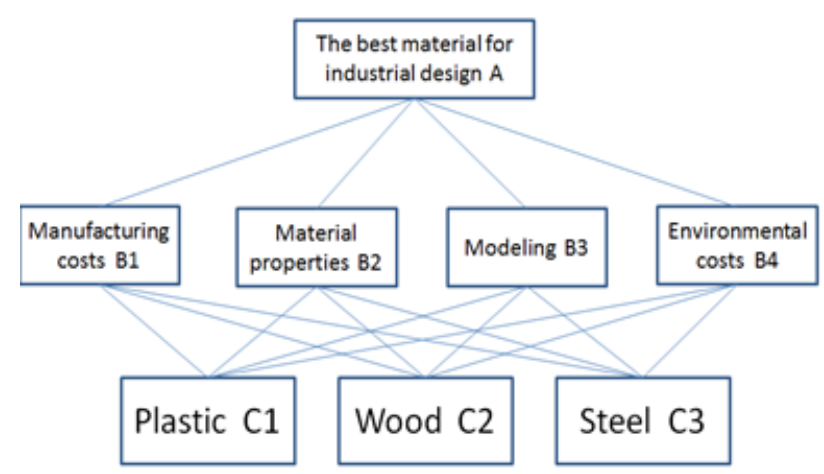

Fig. 1. Hierarchical structure model for material selection

\section{B. Establish a judgment matrix}

Four experts were invited to score the two factors according to the above hierarchy model, as shown in Table II . Then find the average value and get the matrix as shown in Table III. Similarly, the judgment matrix of B-C can be obtained as shown in Table IV-VIII. 
TABLE II. TRIANGULAR FUZZY JUDGMENT MATRIX A-B

\begin{tabular}{|c|cccc|}
\hline A & B1 & B2 & B3 & B4 \\
\hline & $(0.5,0.5,0.5)$ & $(0.6,0.8,0.9)$ & $(0.1,0.2,0.3)$ & $(0.2,0.3,0.4)$ \\
B1 & $(0.5,0.5,0.5)$ & $(0.6,0.7,0.8)$ & $(0.1,0.1,0.3)$ & $(0.2,0.4,0.5)$ \\
& $(0.5,0.5,0.5)$ & $(0.7,0.8,0.9)$ & $(0.1,0.2,0.3)$ & $(0.3,0.3,0.4)$ \\
& $(0.5,0.5,0.5)$ & $(0.7,0.8,0.9)$ & $(0.2,0.2,0.3)$ & $(0.2,0.3,0.4)$ \\
\hline & $(0.1,0.2,0.4)$ & $(0.5,0.5,0.5)$ & $(0.1,0.1,0.2)$ & $(0.1,0.2,0.3)$ \\
B2 & $(0.2,0.3,0.4)$ & $(0.5,0.5,0.5)$ & $(0.1,0.2,0.3)$ & $(0.2,0.2,0.3)$ \\
& $(0.1,0.2,0.3)$ & $(0.5,0.5,0.5)$ & $(0.1,0.2,0.2)$ & $(0.1,0.3,0.4)$ \\
& $(0.1,0.2,0.3)$ & $(0.5,0.5,0.5)$ & $(0.1,0.2,0.3)$ & $(0.1,0.2,0.3)$ \\
\hline & $(0.7,0.8,0.9)$ & $(0.8,0.9,0.9)$ & $(0.5,0.5,0.5)$ & $(0.6,0.8,0.8)$ \\
B3 & $(0.7,0.9,0.9)$ & $(0.7,0.8,0.9)$ & $(0.5,0.5,0.5)$ & $(0.6,0.7,0.8)$ \\
& $(0.7,0.8,0.9)$ & $(0.8,0.8,0.9)$ & $(0.5,0.5,0.5)$ & $(0.6,0.8,0.9)$ \\
& $(0.7,0.8,0.8)$ & $(0.7,0.8,0.9)$ & $(0.5,0.5,0.5)$ & $(0.7,0.8,0.8)$ \\
\hline & $(0.6,0.7,0.8)$ & $(0.7,0.8,0.9)$ & $(0.2,0.2,0.4)$ & $(0.5,0.5,0.5)$ \\
B4 & $(0.5,0.6,0.8)$ & $(0.7,0.8,0.8)$ & $(0.2,0.3,0.4)$ & $(0.5,0.5,0.5)$ \\
& $(0.6,0.7,0.7)$ & $(0.6,0.7,0.9)$ & $(0.1,0.2,0.4)$ & $(0.5,0.5,0.5)$ \\
& $(0.6,0.7,0.8)$ & $(0.7,0.8,0.9)$ & $(0.2,0.2,0.3)$ & $(0.5,0.5,0.5)$ \\
\hline
\end{tabular}

TABLE III. TRIANGULAR FUZZY JUDGMENT MATRIX A-B

\begin{tabular}{|c|cccc|}
\hline A & B1 & B2 & B3 & B4 \\
\hline B1 & $(0.50,0.50,0.50)$ & $(0.65,0.775,0.875)$ & $(0.125,0.175,0.3)$ & $(0.225,0.325,0.425)$ \\
\hline B2 & $(0.125,0.225,0.35)$ & $(0.5,0.5,0.5)$ & $(0.1,0.175,0.25)$ & $(0.125,0.225,0.325)$ \\
\hline B3 & $(0.7,0.825,0.875)$ & $(0.75,0.825,0.9)$ & $(0.5,0.5,0.5)$ & $(0.625,0.775,0.825)$ \\
\hline B4 & $(0.575,0.675,0.775)$ & $(0.675,0.775,0.875)$ & $(0.175,0.225,0.375)$ & $(0.5,0.5,0.5)$ \\
\hline
\end{tabular}

TABLE IV. TRIANGULAR FUZZY JUDGMENT MATRIX B1-C

\begin{tabular}{|c|ccc|}
\hline B1 & C1 & C2 & C3 \\
\hline C1 & $(0.5,0.5,0.5)$ & $(0.325,0.425,0.475)$ & $(0.125,0.175,0.225)$ \\
\hline C2 & $(0.525,0.575,0.675)$ & $(0.5,0.5,0.5)$ & $(0.125,0.25,0.375)$ \\
\hline C3 & $(0.775,0.825,0.875)$ & $(0.625,0.75,0.875)$ & $(0.5,0.5,0.5)$ \\
\hline
\end{tabular}

TABLE V. TRIANGULAR FUZZY JUDGMENT MATRIX B2-C

\begin{tabular}{|c|ccc|}
\hline B2 & C1 & C2 & C3 \\
\hline C1 & $(0.5,0.5,0.5)$ & $(0.575,0.7,0.825)$ & $(0.225,0.35,0.475)$ \\
\hline C2 & $(0.15,0.285,0.45)$ & $(0.5,0.5,0.5)$ & $(0.225,0.325,0.45)$ \\
\hline C3 & $(0.525,0.65,0.775)$ & $(0.55,0.675,0.75)$ & $(0.5,0.5,0.5)$ \\
\hline
\end{tabular}

TABLE VI. TRIANGULAR FUZZY JUDGMENT MATRIX B3-C

\begin{tabular}{|c|ccc|}
\hline B3 & C1 & C2 & C3 \\
\hline C1 & $(0.5,0.5,0.5)$ & $(0.12,0.26,0.35)$ & $(0.62,0.75,0.85)$ \\
\hline C2 & $(0.65,0.74,0.88)$ & $(0.5,0.5,0.5)$ & $(0.78,0.86,0.89)$ \\
\hline C3 & $(0.15,0.25,0.38)$ & $(0.11,0.14,0.22)$ & $(0.5,0.5,0.5)$ \\
\hline
\end{tabular}

TABLE VII. TRIANGULAR FUZZY JUDGMENT MATRIX B4-C

\begin{tabular}{|c|ccc|}
\hline B4 & C1 & C2 & C3 \\
\hline C1 & $(0.5,0.5,0.5)$ & $(0.14,0.17,0.29)$ & $(0.11,0.24,0.36)$ \\
\hline C2 & $(0.71,0.83,0.86)$ & $(0.5,0.5,0.5)$ & $(0.67,0.83,0.89)$ \\
\hline C3 & $(0.74,0.76,0.89)$ & $(0.11,0.17,0.33)$ & $(0.5,0.5,0.5)$ \\
\hline
\end{tabular}

Take Table III as an example:

$\mathrm{w} 1=(0.1639,0.2218,0.3066), \mathrm{w} 2=(0.0929,0.1406,0.2080)$, $w 3=(0.2814,0.3656,0.4526), w 4=(0.2104,0.2719,0.3686)$.
The above results are fed back to the experts and the experts are asked to give the weight of each indicator independently. Find the mean $\mathrm{w}$ and the standard deviation $\sigma$, where 


$$
\begin{gathered}
\mathrm{W}=(0.2183,0.1396,0.3778,0.2643), \\
\sigma=(0.2160,0.1944,0.2041) .
\end{gathered}
$$

Then we feed back the calculation results of the mean and standard deviation to the expert, asking the expert to redetermine the weight on this basis. Reciprocating until the opinions of experts are basically the same, and the final weight $\mathrm{W}_{A-B}=(0.2168,0.1465,0.3848,0.2519)$. Similarly, the weight of $\mathrm{B}-\mathrm{C}$ can be obtained as follows:

$$
\begin{aligned}
& w_{B-C 1}=(0.1254,0.2304,0.6442), \\
& w_{B-C 2}=(0.2958,0.1683,0.5359), \\
& w_{B-C 3}=(0.2256,0.6921,0.0823), \\
& w_{B-C 4}=(0.0868,0.6897,0.2235) .
\end{aligned}
$$

Finally get the total sort weight W:

$$
\begin{aligned}
W & =\left(\begin{array}{llll}
0.1254 & 0.2958 & 0.2256 & 0.0868 \\
0.2304 & 0.1683 & 0.6921 & 0.6897 \\
0.6442 & 0.5359 & 0.0823 & 0.2235
\end{array}\right)\left(\begin{array}{l}
0.2168 \\
0.1465 \\
0.3848 \\
0.2519
\end{array}\right) \\
& =\left(\begin{array}{l}
0.1792 \\
0.5147 \\
03061
\end{array}\right)
\end{aligned}
$$

According to the weight value, it can be concluded that the best material for making the above-mentioned chair is wood.

\section{CONCLUSION}

- The improved fuzzy analytic hierarchy process introduces triangular fuzzy numbers, allowing experts to make estimates and trade-offs when making judgments. It can better reflect the experts' understanding of the interrelationship between indicators, reduce the errors brought about by subjective judgments of experts, and bring the role of experts to the extreme.
- In combination with the Delphi method, the investigation of experts' views on issues was repeated, inquired, summarized, and modified. Finally, they were summarized into a consensus among experts. This fully utilizes the experience and knowledge of experts and is more reliable. And the experts are more clearly when scoring, and will not cause confusion.

- The Analytic Hierarchy Process (AHP) is the preferred method for selecting materials in industrial design. The article selects the best material for the chair and uses the improved fuzzy analytic hierarchy process to select the best material.

\section{REFERENCES}

[1] A. Majumdar, B. Sarkar, and P. Kumar Majumdar, "Application of analytic hierarchy process for the selection of cotton fibers," Fibers and Polymers, vol. 5, pp. 297-302, December 2004.

[2] J. Zhang, "Research on Personal Information Security Evaluation Based on Analytic Hierarchy Process," Value Engineering, vol. 5, pp. 57-60, 2018. (In Chinese).

[3] J. Zhang, X. Han, and Z. Ma. "Cost control of apartment house based on analytic hierarchy process," Journal of Shenyang University of Technology, vol. 6, pp. 716-720, 2017. (In Chinese).

[4] J. Du, J. Huang, Bo Xiao, Hong Han. "Improved block storage scheduling algorithm based on triangular fuzzy number," Information Technology, vol. 9, pp. 9-13, 2017. (In Chinese).

[5] Z. Xu, Q. Da, "Method based on fuzzy linguistic scale and FIOWGA operator for decision-making problems,” Journal of Southeast University (English Edition), vol.1, pp.88-91, 2003.

[6] S. Zhang, Y. Chao, B. Yuan. "Research on High Speed Cutting Speed Optimization Based on FAHP,” Modular Machine Tool \& Automatic Manufacturing Technique, vol.1, pp.4-7, 2018. (In Chinese).

[7] R. Li, Y. Jiang, and Y. Ren. "An Acquisition and Selection Model of Foreign Language Books Based on Delphi Methods and AHP,” New Century Library, vol.1, pp. 40-43, 2018. (In Chinese).

[8] S. Xu. "A Method for Priorities of Triangular Fuzzy Number Complementary Judgment Matrices,” Fuzzy Systems and Mathematics, vol.1, pp. 47-50, 2002. (In Chinese). 